\section{A performance circense no Primeiro Cinema}

\section{Circus performance in Early Cinema}

\section{Raquel Magalhães}

Universidade Estadual de Campinas. Instituto de Artes.

\section{RESUMO}

O presente artigo tem por objetivo analisar de que maneiras a performance circense e a imagem-movimento se aproximam no contexto do primeiro cinema.Paratanto,foianalisadoumcorpo fílmico composto por6filmesamericanos protagonizando performances de circo entre 1894-1901, através de uma análise histórica preliminar do primeiro cinema e do ambiente dos vaudevilles e de uma descrição ponto a ponto, baseada em autores como Gunning (1990), Costa (1995), Machado (1997) e Stoddart (2015), visando abordar os temas tanto do ponto de vista da captação de imagem como da arte circense enquanto performance de risco. Concluiu-se que as

\section{6} historical analysis of Early Cinema and the vaudeville setting, and a thorough description, based on authors such as Gunning (1990), Costa (1995), Machado (1997) and Stoddart (2015), aiming to approach these themes through the lenses of both motion capture and circus as risk performances. It was concluded that both arts are alike in terms of exhibitionism, scopophilia, autonomy of the acts, shared public and content, duas artes se aproximam em termos de exibicionismo, escopofilia, autonomia, divisão de público e de conteúdo, e se potencializam a partir das possibilidades da reprodutibilidade do cinema. Porém, se distanciam em razão de natureza e admiração das artes, além do cinema ser desfavorável às artes circenses em função da extinção do risco e quebra da tensão inerentes ao circo, e da incompatibilidade entre imobilidade da câmera e dinamicidade da performance.

PALAVRAS-CHAVE: primeiro cinema, circo, vaudeville, reprodutibilidade, risco. and leverage one another through the possibilities of mechanical reproduction in cinema. However, they differ in terms of the nature and allure of the arts, and due to the fact that cinema is unfavorable to circus in terms of elimination of risk and tension that are inherent to circus, and the incompatibility between the camera's imobility and the dynamism of performance.

KEYWORDS: early cinema, circus, vaudeville, mechanical reproduction, risk. 


\section{INTRODUÇÃO}

Um acrobata de collant demonstra suas habilidades de contorcionismo, segurando os pés e equilibrando-se em duas argolas. Ele olha diretamente para a câmera e sorri, antes de fechar o semblante e continuar seu ato. Ele então sai de sua posição inicial e gira em seu próprio eixo em outra demonstração de flexibilidade. 0 filme, de 16 segundos, acaba. Estamos falando de Luis Martinetti, um filme de 1894, produzido pela companhia Edison, retratando o ato do contorcionista de mesmo nome.

Filmes como este eram muito comuns na virada do século XIX. Como descreve Flávia Costa:

Até 1906, os filmes de atualidades ou pequenas gags, iguais às que eram encenadas no circo ou nos vaudevilles, superavam em número os filmes de ficção, já que a maioria dos filmes encenados não tinha pretensão narrativa. Em geral, os filmes exibidos nos vaudevilles incluíam filmagens dos próprios números encenados nos vaudevilles, além de números de magia e ilusionismo, e quadros vivos sobre temas religiosos ou populares, muitas vezes retratados em músicas, piadas e cartoons. Incorporados às atrações de feiras típicas do século XIX, circos, espetáculos itinerantes e encenações burlescas, tais filmes não eram, definitivamente, produtos acabados. As apresentações constavam de filmes curtos, compostos na sua maioria por apenas um plano. (1995, p. 17)

Considerando o contexto de 1895-1906 (período anterior à narrativização do cinema), quais eram os interesses dos primeiros cineastas em gravar cenas como estas? De que forma a gravação dessas performances era benéfica para o artista protagonista, em detrimento à performance ao vivo?

O objetivo deste artigo é analisar de que maneiras a performance circense e a imagem-movimento se aproximam no contexto do primeiro cinema. Para isso, será usado um corpo fílmico pré-determinado de filmes americanos com performances de circo entre 1894-1901, composto por 6 filmes. O corpo fílmico em questão será:

\begin{tabular}{|l|l|}
\hline \multicolumn{1}{|c|}{ FILME } & \multicolumn{1}{c|}{ TIPO DE PERFORMANCE } \\
\hline Annabelle Butterfly Dance (1894) & Dança \\
\hline Caicedo (with pole) (1894) & Funambulismo; Aéreos \\
\hline Luis Martinetti (1894) & Contorcionismo; Aéreos \\
\hline Sandow (1894) & Halterofilismo \\
\hline Three acrobats (1899) & Palhaços \\
\hline Trapeze disrobing act (1901) & Aéreos; Peep Show \\
\hline
\end{tabular}

É importante notar, também, que se utiliza neste texto o conceito de primeiro cinema reapropriado do inglês (early cinema) por Flávia Cesarino Costa, que designa para a autora "os filmes e práticas a eles correlatas surgidos no período que os historiadores costumam localizar, aproximadamente, entre 1894-5 e 1906-8. É a chamada primeira década do cinema." (1995, p. 8).

Para analisar tais questões, começaremos delineando alguns pontos históricos do primeirocinema, do períodoem questão,comfoconos Estados Unidos.Descreveremos então brevemente os espaços e atos do vaudeville. Em seguida, analisaremos ponto a ponto como as artes circenses e o primeiro cinema se aproximam (ou se distanciam).

\section{O QUINETOSCÓPIO E OS VAUDEVILLES}

O quinetoscópio, um dos primeiros aparatos de captação e exibição de imagens em movimento, surge em 1894, nos Estados Unidos. Patenteado por Thomas Edison, "possuía um visor através do qual se podia assistir, mediante a inserção de uma moeda, à exibição de uma pequena tira de filme onde apareciam imagens em movimento de lutas de boxe, bailarinas, cenas eróticas, números cômicos, animais amestrados ou quadros da Paixão de Cristo" (COSTA, 1995, p. 10-11). Tais imagens eram gravadas com o quinetógrafo, criado em 1887 por William Kennedy Laurie Dickson. Patenteada 
em 1891, "é a câmera com a qual todos os filmes nos Estados Unidos, até 1896, foram filmados" (COSTA, 1995, p. 11).

Filmes eram exibidos em muitos espaços além dos salões e parques dos quinetoscópios, e de forma individualizada e em exibições públicas. Como descreve Flávia: "Os primeiros filmes apareceram em 1895. Começaram a ser exibidos em feiras, circos, teatros de ilusionismo, parques de diversões, cafés e em todos os locais onde havia espetáculos de variedades. Mas o principal local de exibição de filmes eram os vaudevilles." (COSTA, 1995, p. 14).

Entre 1895 e 1900, o vaudeville era a forma dominante de exibição de filmes (apesar de não ser a única) (COSTA, 1995, p. 26). Um espaço de entretenimento nos Estados Unidos cuja a essência era a variedade: com um programa repleto de música, comédia e drama, além de espetáculos de circo, atos de menestrel, ele apelava para um público misto e familiar (LEWIS, 2007, p. 315). Além de atos teatrais e de artes circenses, as mais novas invenções da ciência também eram exibidas e tinham seu próprio espaço, como "gramofones, tel-ectric e quinetoscópios" (LEWIS, 2007, p. 331). Porém, ao realizar sua estratégia de vendas de quinetoscópios e vitascópios (projetor criado em 1896) ao redor do país, Thomas Edison não privilegiou a rede americana de vaudevilles e teatros de variedades, como faziam seus concorrentes franceses irmãos Lumière, o que levou à falência de Edison em 1896 (COSTA, 1995, p. 13).

Devido a esse esquema, nos vaudevilles, "até em torno de 1910, o primeiro cinema era só um número entre uma variedade de "atos" que apareciam ao lado de outras formas de entretenimento teatral e itinerante, dentre as quais o circo era, pelo menos até o final do século dezenove, a forma dominante" (STODDART, 2015, p. 8).

Podemos, a partir destas afirmações, delinear duas características determinantes do primeiro cinema. Como já estabelecido, uma característica fundamental é a de "serem atrações autônomas, que se encaixavam facilmente nas mais diferentes 140 programações". Isso faz com que a maioria dos filmes, desse primeiro período entre 1894 e 1906-1907, sejam "em sua ampla maioria compostos por uma única tomada, (...) pouco integrados a uma eventual cadeia narrativa" (COSTA, 1995, p. 16).

A segunda característica, que observaremos também no corpo fílmico delimitado, é a ruptura da diegese em prol de uma "confrontação exibicionista": "o observador é repetidamente chamado a participar da cena e responder aos acenos e piscadelas dos atores que se dirigem ostensivamente à câmara e deixam claro que sabem de nossa presença" (COSTA, 1995, p. 7). Neste texto usaremos a definição de Marc Vernet do olhar para a câmera como "um plano isolado, ou, ao menos, um plano que não tenha um contraponto ou resposta simétrica em algum outro momento do filme" (1989, p. 51).

Considerando, então, que "até 1906, o cinema está, portanto, ligado ao espetáculo de variedades, que era a principal forma de exibição de filmes" (COSTA, 1995, p. 23), o contexto histórico dos Estados Unidos entre 1894-1901 na primeira década do cinema e os filmes que retratavam atos de vaudeville, gravados principalmente com o quinetógrafo pela produtora de Thomas Edison, focarei minha pesquisa em filmes de atos relacionados tradicionalmente ao circo, como performances de aéreos, funambulismo, palhaços e acrobacias. Além disso, do corpo fílmico descrito acima, apenas "Trapeze disrobing act" (1901) e "Three acrobats" (1899) parecem não terem sido gravados com quinetógrafo, devido aos anos de produção encontrados.

\section{AS POSSIBILIDADES DA PERFORMANCE CIRCENSE NO PRIMEIRO CINEMA}

\section{Exibicionismo}

Partindo da definição de Tom Gunning (1990) de "cinema de atrações", que define o assunto do primeiro cinema como "a própria habilidade de mostrar alguma coisa" (p. 57), podemos começar argumentando que esse exibicionismo (STODDART, 2015) é 
comum ao cinema e ao circo.

É possível caracterizar o primeiro cinema como exibicionista pois, como exposto anteriormente, "o observador é repetidamente chamado a participar da cena e responder aos acenos e piscadelas dos atores que se dirigem ostensivamente à câmara e deixam claro que sabem de nossa presença" (COSTA, 1995, p. 7). Como desenvolve Tom Gunning, "contrastado ao aspecto voyeurístico do cinema narrativa analisado por Christian Metz, esse é um cinema exibicionista", devido principalmente a tal olhar recorrente à câmera pelos atores (1990, p. 57). Dentro da visão de Marc Vernet definida neste texto, de acordo com a teoria tradicional, o olhar para a câmera possui "um efeito duplo: ele traz à tona a instância enunciativa do texto fílmico e ataca o voyeurismo do espectador ao colocar o espaço do filme e o espaço do teatro brevemente em contato direto" (VERNET, 1989, p. 48).

Já no circo, o "corpo é mecanismo, vetor, quadro e ator" (WALLON, 2009, p. 18) em um só, além de ser "uma ópera para os olhos" (PENCENAT, 2009, p. 43), um espetáculo ocular/visual (DE BLAS \& MATEU apud BORTOLETO \& MACHADO, 2003, p. 46). Como descrito por Caroline Caffin (1914):

“Tão pouco tempo é concedido a cada artista que seu apelo é necessariamente franco e direto. Não se esconde atrás de sutilezas, mas é pessoal e sincero. Encara a plateia e diz, de fato, "Olhe para MIM! Eu quero te surpreender!" Não pretende ser indiferente ou impessoal, mas desce logo na ribalta e no rosto do público e diz "Tudo para o seu Deleite! Nós estamos - aqui."..." (LEWIS, 2007, p. 328, tradução nossa)

Ora, é possível notar que elementos como o olhar recorrente ao espectador/à câmera; a constante chamada do espectador a participar (através de acenos e piscadelas); e a própria habilidade de mostrar algo - seja no circo, com a natureza do ato, ou seja no cinema, com a "fascinação por seu poder ilusório (...) e exoticismo" (GUNNING, 1990, p. 57) - são comuns ao primeiro cinema e ao circo.

Além disso, como explora Helen Stoddart, o "exibicionismo" através de uma "sucessão de performances não-narrativas e quase ilógicas", afirmação feita para o cinema (GUNNING apud STODDART, 2015, p. 9), pode ser usada também para o circo, "com a sua solicitação direta da atenção da audiência e processão de atos sem a necessidade de lógica ou continuidade operando entre eles" (STODDART, 2015, p. 9).

Assim, considerando o exibicionismo característico do Primeiro Cinema, e a natureza de espetáculo visual exibicionista do circo, as artes circenses são um excelente tema para essa tecnologia emergente.

Ao nos virarmos para nosso corpo fílmico, isso se torna claro na maioria deles: em Luis Martinetti (1894), ao iniciar sua sequência, o acrobata olha diretamente para a câmera [Figura 1]; em "Annabelle Butterfly Dance" (1894), a dançarina mantém contato visual com a câmera durante quase toda performance; em Three acrobats (1899), os palhaços recorrentemente acenam e gesticulam para a câmera, indicando quais seus próximos atos ou despedindo-se do público.

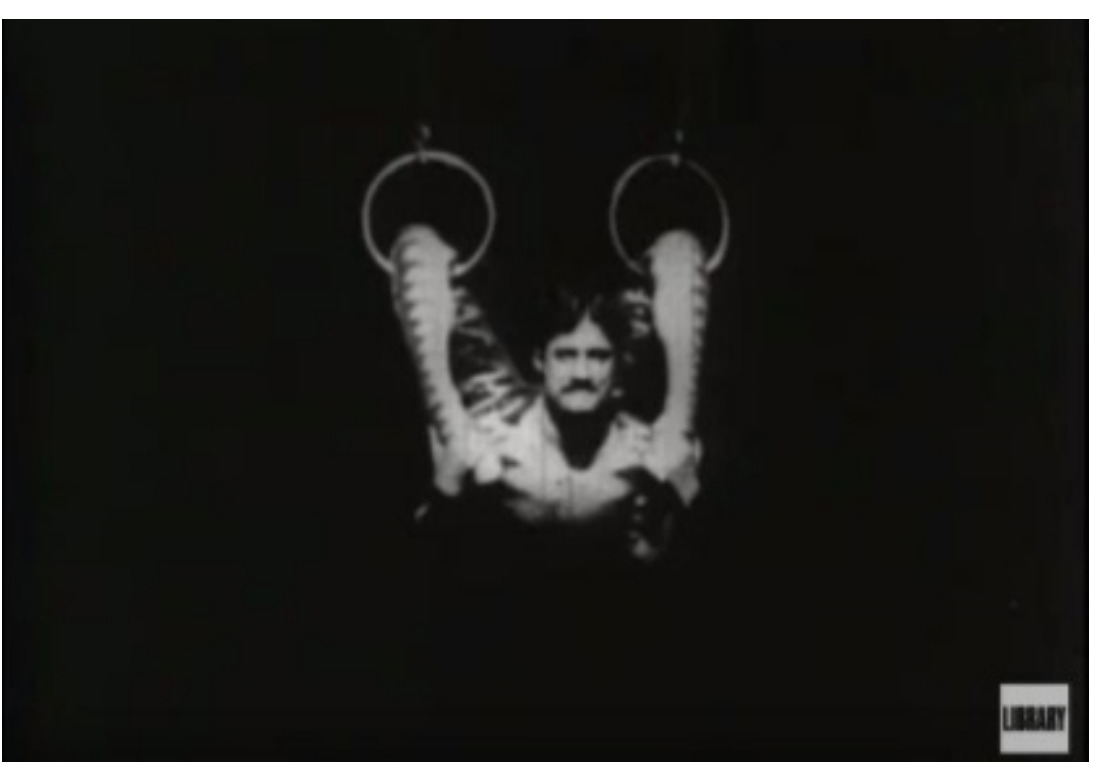

Figura 1: Acrobata olhando diretamente para a câmera em Luis Martinetti (1894) 


\section{Escopofilia}

Também é possível associar o exibicionismo do cinema e das artes circenses a um aspecto escopofílico do primeiro. Arlindo Machado (1997) aponta essa característica dos filmes do Primeiro Cinema, que eram vistos, no início, em sua maioria em pequenos visores, como é o caso de maioria dos filmes do corpo fílmico aqui trabalhado:

As primeiras imagens cinematográficas, no sentido atual do termo, não foram as do cinematógrafo dos irmãos Lumière, mas as do mutoscópio e do quinetoscópio, ou seja, imagens concebidas para a visualização privada, imagens, portanto, destinadas a ser "espiadas" através de visores individuais. Não por acaso, os temas, os motivos da maioria dos filmes produzidos para essas formas individuais de cinema evocam inevitavelmente a escopofilia, ou seja, o erotismo do olhar, o desejo embutido no ato de ver: a dança em estilo borboleta de Annabelle, a dança do ventre de Fátima, a dança da paixão de Dolorita, o beijo de May irwin e John C. Rice, a mulher nua que surge como uma pérola de dentro de uma concha, garotas em trajes de dormir brincando de guerra de travesseiros e também, se preferirmos um exemplo masculino, as demonstrações de musculatura do halterofilista Eugene Sandow. (MACHADO, 1997, p. 124)

Como o próprio autor indica, os filmes "Annabelle Butterfly Dance" (1894) e "Sandow" (1894) tem o aspecto escopofílico em si. Ao explorarmos "a lente cinematográfica (...) como um olho protético", nos conceitos de Elsaesser e Hagener, no primeiro cinema "o olho descorporificado era celebrado como uma ilusão convincente de poder e onipotência" (ELSAESSER; HAGENER, 2018, p. 103-104). Segundo Machado, uma vez que as tomadas do quinetoscópio pressupunham um "visor de ampliação", através do qual o espectador veria a cena, o enquadramento se torna mais aproximado que aquele do cinematógrafo. É justamente por essa razão que "o halterofilista Sandow aparece enquadrado da barriga para cima", segundo o autor (MACHADO, 1997, p. 144 acrobacias. Apesar do show ser "voltado para" os cavaleiros e a acrobata gesticular para eles durante a performance, o enquadramento éfeito de forma a ser o espectador o público desse strip-tease. Ao final do filme, a acrobata acena e sorri diretamente para a câmera [Figura 2].

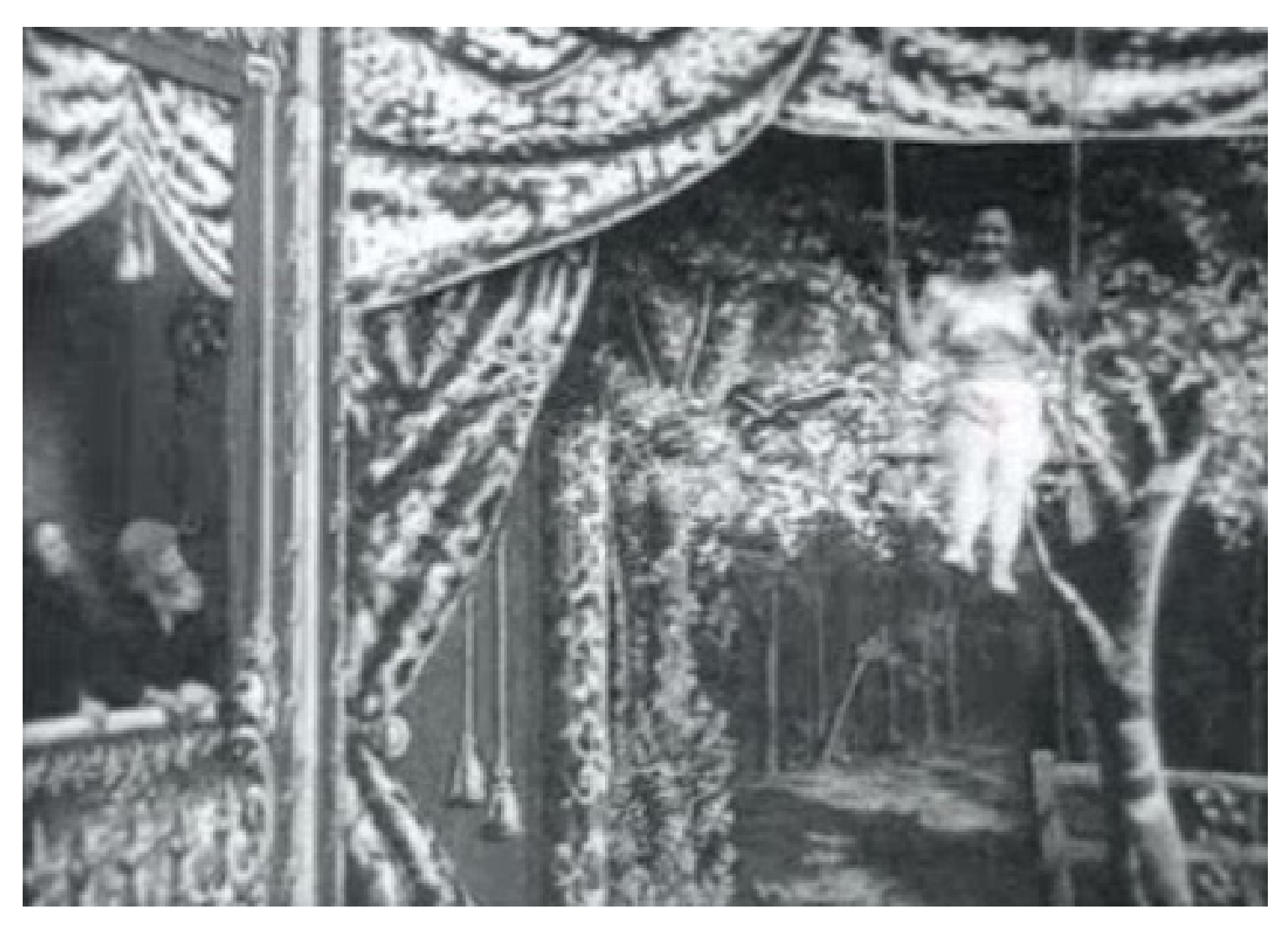

Figura 2: Acrobata sorrindo para a câmera ao final de "Trapeze disrobing act" (1901)

Em filmes como "Trapeze disrobing act" (1901), podemos aplicar a afirmação de Elsaesser e Hagener sobre a teoria feminista da "natureza fálica do olho questionador, inquisitivo", em que "o olhar (masculino) de poder sobre o corpo (feminino) é exibido diretamente em sua natureza voyeurística" (2018, p. 106). Ao associarmos esse aspecto escopofílico ao olhar para a câmera (presente também em "Annabelle Butterfly Dance"), podemos afirmar que o olhar para a câmera "chama para uma união que todos sabem impossível, e cuja atração (...) reside em tal impossibilidade" (VERNET, 1989, p. 56). 


\section{Autonomia}

Além do caráter exibicionista e escopofílico, o circo se aproxima do cinema por se tratar de uma performance enclausurada em um universo fechado sobre si mesmo, cuja temporalidade não remete a nenhuma referência exterior (ABIRACHED, 2009, p. 172), o mesmo podendo ser afirmado para o cinema, cujo "retângulo da imagem é visto como uma espécie de janela que abre para um universo que existe em si e por si" segundo Ismail Xavier (1984, p. 15). E como define Gunning (1990), o primeiro cinema provê "prazer através de um espetáculo emocionante - um evento único, seja ficcional ou documental, que é de interesse em si mesmo" (p. 58), tornando as performances circenses um ótimo tema para o cinema da virada do século.

Helen Stoddart também já havia analisado essa relação em seu artigo:

O fato de tantos filmes europeus e norte-americanos exibirem circos ou performances circenses sugere que cineastas até 1910 estavam de olho no fato de os circos terem ainda grandes públicos nas primeiras décadas do século $X X$, e portanto abraçaram o que, à primeira vista, poderia parecer o assunto ideal para seu entretenimento baseado nos espetáculos. (2015, p. 3, tradução nossa)

\section{Temas, público e espaços compartilhados}

Como desenvolve Lewis (2007), as classes baixas, que frequentavam os circos, se interessavam também pelos vaudevilles e pelos "the penny-in-the-slot Arcades", esse último composto por quinetoscópios, mutoscópios, vitoscópios, ou fonógrafos, que ofereciam peepshows sem som ou trechos de uma música (LEWIS, 2007, p. 16). Logo, o público das diferentes formas de entretenimento, entre vaudevilles, teatro de variedades, lanterna mágica, feiras e circos, era essencialmente o mesmo, tendo domínio da linguagem desses espaços.

Não podemos deixar de salientar, então, que além da divisão de público interessada 146 em ambas formas de entretenimento, os públicos do circo e do cinema também dividiam o mesmo espaço físico (STODDART, 2015,p.3).Como definido anteriormente, no início "os filmes foram exibidos como curiosidades ou peças de entreato nos intervalos de apresentações ao vivo em circos, feiras ou carroças de mambembes" (MACHADO, 1997, p. 78). Então, a exibição de filmes nos centros urbanos passou para casas de espetáculos de variedades, entre eles, os vaudevillesnos Estados Unidos. Foi nesses espaços que "em pleno apogeu da virada do século, que o cinema floresceu com maior vigor." (MACHADO, 1997, p. 78).

Dentro do Vaudeville, o cinema não compartilhava apenas o espaço físico e o público das artes circenses, como também os temas:

No período que vai de 1895 (data das primeiras exibições públicas do cinematógrafo dos Lumière) até meados da primeira década do século seguinte, os filmes que

se faziam compreendiam registros dos próprios números de vaudeville, ou então atualidades reconstituídas, gags de comicidade popular, contos de fadas, pornografia e prestidigitação. Os catálogos dos produtores da época classificavam os filmes produzidos como "paisagens", "notícias", "tomadas de vaudeville", "incidentes", "quadros mágicos", "teasers" (eufemismo para designar a pornografia) etc. (MACHADO, 1997, p. 80)

Em suma, os Vaudevilles foram um espaço de partilha entre as artes circenses e o cinema. No quesito do tema, como explorado anteriormente, existem grandes convergências entre os dois campos, além de ter sido comum na época filmarem os atos das casas de variedades. Quanto ao público, os públicos de circo e cinema eram partilhados tanto dentro quanto fora dos vaudevilles.

Estabelecido onde as artes circenses e o cinema se convergem, é necessário refletir onde esses campos se distanciam e/ou entram em conflito. 


\section{Reprodutibilidade: risco e tensão}

Como expõe Benjamin, "no cinema temos uma forma, cujo caráter da arte, pela primeira vez é determinado de parte a parte por sua reprodutibilidade" (BENJAMIN, 2014, p. 51). O autor distancia a performance do ator cinematográfico daquela do ator de teatro, aproximando seu desempenho artístico do desempenho de um atleta (BENJAMIN, 2014, p. 61). Podemos aplicar a mesma lógica do ator cinematográfico para a performance artística de um "acrobata cinematográfico". Ao contrário do palco, durante a filmagem, o acrobata tem a possibilidade de realizar inúmeras tentativas, até atingir sua "melhor performance", que será selecionada pelo diretor ou produtor para ser exibida. Como define Benjamin: "o cinema torna exibível o desempenho de teste, ao transformar, em um teste, a própria exponibilidade do desempenho" (2014, p. 65).

Assim, além de garantir a perfectibilidade da performance, a reprodutibilidade do filme protege a saúde do artista e os "riscos da profissão" (GOUDARD, 2009, p. 28). Ou seja, o artista de circo realizando "uma performance equivalente à de um atleta de alto nível", diversas vezes por dia e centenas por ano, sua saúde, integridade física e até mesmo sua vida são constantemente arriscadas. Porém, ao ter um artifício que grava sua performance, podendo ela ser reproduzida centenas de vezes, ele se expõe menos ou apenas uma vez (o ato da filmagem) a tais riscos.

Além disso, ainda falando da reprodutibilidade, como define Machado, o tempo é um elemento "transformador", "capaz de abalar a própria estrutura da matéria, de comprimi-la, dilatá-la, multiplicá-la, torcê-la até o limite da transfiguração" (1997, p. 60). Ou seja, um ato circense pode ser explorado de maneiras que a performance real, em carne e osso na lona, não permite, por exemplo desacelerando, acelerando ou parando a cena.

Contudo, o risco é uma característica inerente ao circo, e eliminá-lo mexe diretamente 148 com a natureza da performance. Segundo Goudard, a base da linguagem do circo é constituída por uma "sucessão de situações estáveis estáticas ou dinâmicas, retomadas por momentos de ruptura, de desequilíbrio, onde se desencadeiam as figuras e se corre perigo" (2009, p. 26). E Mandell propõe que, no circo, a "espetacularização do risco é explorada ao máximo, pondo em tensão os limites entre o real e o construído artisticamente" (2016, p. 73), sendo o risco físico "um dos principais e mais explorados recursos da linguagem circense" (idem, p. 78). De acordo com os autores, ao longo do número, "o risco fica cada vez maior e mais evidente" e "a intensidade das variações estabelecidas relativamente pelo artista na posição estável oferecem ao seu espetáculo uma tensão" (MANDELL, 2016, p. 73) (GOUDARD, 2009, p. 27). Apesar do artista criar propositalmente tais situações de desestabilidade e se expor ao perigo voluntariamente, "o risco sobrepõe à ação cênica a ação real, que pode ser elaborada e construída artisticamente, mas que não perde por um segundo o vínculo com a realidade" (MANDELL, 2016, p. 79).

Temos, aqui, a diferença fundamental que o dispositivo postula sobre o circo: no palco, o risco é real; no cinema, o risco é virtual. Com o aparato do cinema, esse risco é extinto quase que completamente e a tensão do número quebrada. O risco só é real no ato da gravação, enquanto o risco contido dentro do filme é virtual. Ao mesmo tempo, falando da tensão do número, ao interromper a performance, encurtá-la, ou selecionar apenas um movimento do todo do espetáculo, quebra-se a tensão gradual característica do circo.

Ainda falando de risco, nas performances circenses a virtualidade da morte está sempre presente: "o risco como devir de morte está obstinadamente presente na poética e estética do circo" (MANDELL, 2016, p. 77). Até mesmo Bazin realiza esta comparação, ao dizer que touradas (no filme "A Corrida de Toros", 1949) brincam "com a vida, como o trapezista sem rede" (1983, p. 132). Porém, no circo, a morte 
é única; no cinema, é repetida e infinita. Como explora Bazin, a morte é um evento "de especificidade cinematográfica": "o cinema possui o exorbitante privilégio de repeti-Io" (1983, p. 132). Dessa forma, fosse o caso de uma performance circense filmada acabar em morte, mortalidade esta que é sempre virtual no circo, o cinema potencializaria esse momento, multiplicaria "a qualidade do momento original pelo contraste de sua repetição". De um lado, a presença virtual da morte; do outro, a reprodutibilidade da morte.

\section{Distanciamento ontológico das artes}

Além disso, quando tratamos de circo (e de outras performances do corpo), a presença é um diferencial. No espetáculo, neste caso de circo, "a presença recíproca, o confronto em carne e osso de espectador e ator, não é uma mera circunstância física, mas um fato ontológico". Logo, como expõe Bazin, algo que o (fracasso do) teatro filmado já demonstrou é que "a filmagem do espetáculo não faz mais do que restituí-lo esvaziado de sua realidade psicológica: um corpo sem alma" (1983, p. 132).

Assim, a reprodutibilidade e a montagem (nesse caso, através da seleção, por se tratar de planos únicos) no cinema, que são as mesmas que protegem a saúde do artista e garantem a perfectibilidade da sua performance, são as características que mais se opõe às artes da cena, como já expôs Benjamin (2014, p. 71).

\section{Construção de cena: imobilidade vs. dinamicidade}

Outra característica comum ao circo e ao cinema é o espaço já configurado de miseen-scene. Ou seja, (alguns) atos de circo "são mais facilmente adaptados a espaços teatrais relativamente confinados", não incluindo "movimentos rápidos pelo espaço como um elemento intrínseco de suas performances, algo que estaria além da 150
Primeiro Cinema "confronta o público com as limitações de uma câmera incapaz de imitar o olhar e consequentemente também é incapaz de alcançar as demandas feitas a ele pelo corpo do acrobata em movimento no ar" (STODDART, 2015, p. 5). Ao analisarmos o corpo fílmico, isso é evidente no filme "Caicedo (with pole)" (1894). Nesse, ao mover-se, a cabeça do acrobata é cortada pelo plano [Figura 3]. Além disso, as performances selecionadas devem se manter dentro do plano, sendo performances dinâmicas como trapézio volante incompatíveis com o Primeiro Cinema.

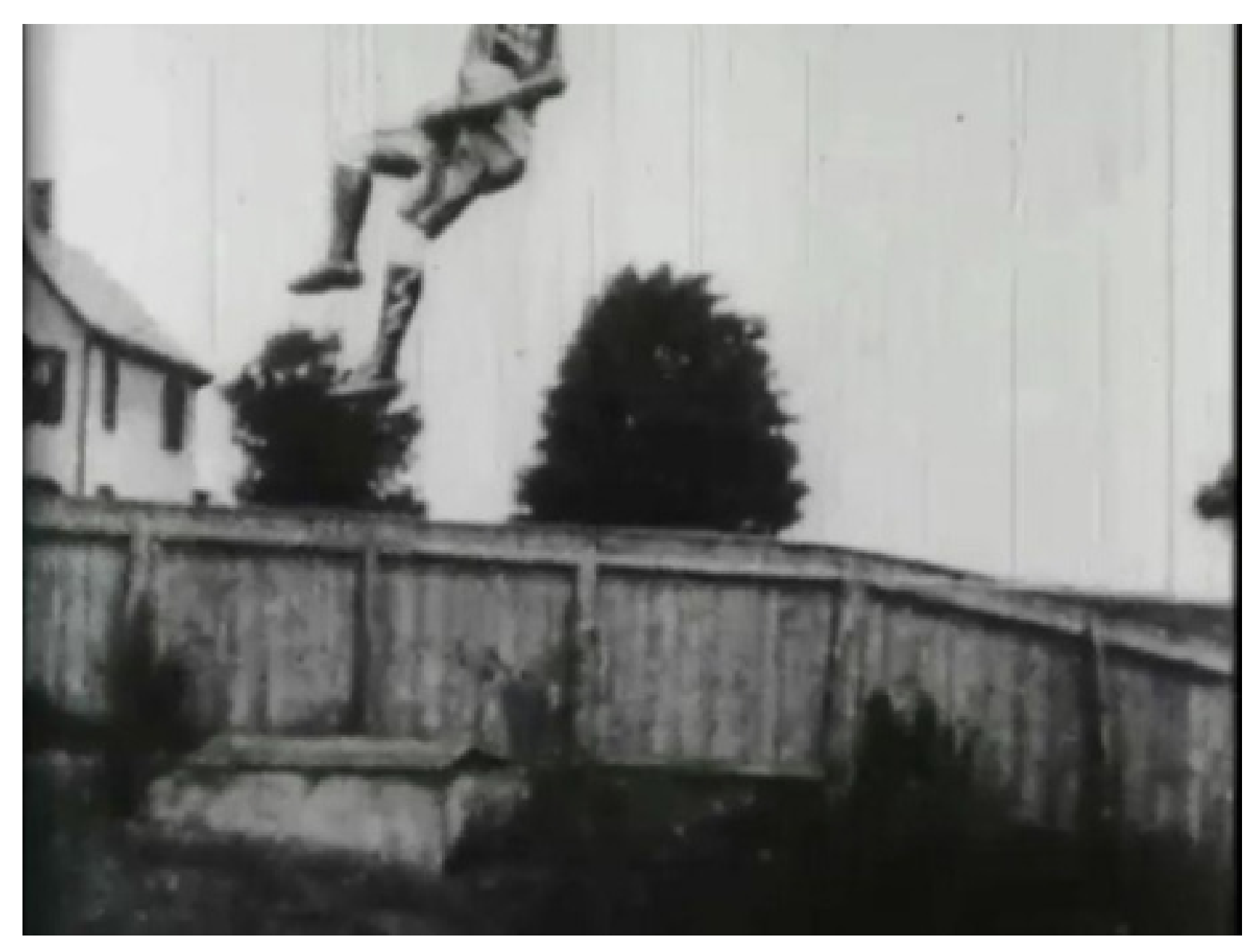

Figura 3: Cabeça do acrobata cortada pelo plano em "Caicedo (with pole) "(1894)

Ademais, é simplista e superficial afirmar que, devido à semelhança da mise-en-scène a um palco, ontologicamente ambas construções (teatral e cinematográfica) são as mesmas. Como explora Ismail Xavier: 
"Mesmo num filme constituído de um único plano fixo e contínuo, pode-se dizer que algo de diferente existe em relação ao espaço teatral, e também em relação ao espaço pictórico (especificamente o da pintura) ou mesmo o fotográfico: a dimensão temporal define um novo sentido para as bordas do quadro, não mais simplesmente limites de uma composição, mas ponto de tensão originário das transformações na configuração dada." (XAVIER, 1984, p. 15)

\section{Admiração e fascínio}

Outra diferença entre essas duas formas de entretenimento são as diferentes fontes de admiração e fascínio de cada um. Como explora Stoddart, enquanto é "o feito técnico da representação mediada em si", a impressão de realidade do cinema que causa admiração no público, é o "feito encenado pela presença performática de corpos humanos" que causa tal fascínio no circo ao vivo, sendo este segundo incapaz de ser capturado pelo cinema (STODDART, 2015, p. 10).

\section{CONSIDERAÇÕES FINAIS}

Como estabelecido pelo contexto histórico exposto na introdução, o primeiro cinema é baseado no exibicionismo e na autonomia, não-narratividade de seus filmes, o que encaixava perfeitamente nos espaços do vaudeville.

Ao analisarmos o corpo fílmico, notamos primeiramente que o exibicionismo ("solicitação da atenção do espectador", "confrontação exibicionista" segundo Stoddart (2015)) é comum às artes circenses e ao primeiro cinema, aproximando-os e tornando o tema das performances atraente para o cinema, que Machado (1997) aponta ter também caráter escopofílico em casos como esses.

Além disso, as duas formas de entretenimento se aproximam por seu arranjo ou "sequência não-narrativa e ilógica de performances" (STODDART, 2015). A 152 performance sendo enclausurada em um universo fechado sobre si mesmo funciona dentro do esquema de autonomia do primeiro cinema, resultando em uma das categorias de filmes ser chamada de "tomadas de vaudeville" (MACHADO, 1997, p. 80). Em troca, a reprodutibilidade do cinema parece favorável às performances circenses por manter a saúde e segurança do artista, além de garantir um melhor desempenho do acrobata e permitir uma transfiguração temporal.

Concluímos também que os atos circenses são mais facilmente adaptados ao espaço confinado da mise-en-scene, e o público do circo e do cinema era essencialmente o mesmo, seja por dominarem as mesmas linguagens ou por dividirem o espaço físico comum do vaudeville.

Por outro lado, no filme, o risco e a tensão da performance, características e recursos de linguagem inerentes do circo, são extintos/quebrados, afetando diretamente a natureza da performance. Ademais, uma diferença basilar entre o risco no cinema e no circo é a sua natureza: de um lado, o risco virtual do cinema, do outro, o risco real do circo. Tal discussão é expandida ao refletirmos a respeito da virtualidade da morte em performances circenses e da sua potencialização através da reprodutibilidade do cinema.

Também apontamos para a existência de uma incompatibilidade entre a imobilidade da câmera e a dinamicidade do circo em alguns atos. No quesito ontológico, a natureza, a construção das cenas e a admiração das duas formas de entretenimento têm origens diferentes: no cinema, vêm da reprodutibilidade, da dimensão temporal e do feito técnico respectivamente; no circo, vêm da performance real dos corpos em cena.

É necessário pontuar, todavia, que tais reflexões só são cabíveis em determinado período. Com o início da narrativização do cinema, são abertas as primeiras salas e espaços próprios para cinema; com o fim do "cinema de atrações", findam-se também 
os espaços Vaudeville. Apesar do circo continuar a ser um tema recorrente ao longo da história do cinema, ele passa a ser explorado dentro de narrativas ficcionais mais delimitadas (STODDART, 2015, p. 6).

Outras questões que podem ser abordadas em futuras pesquisas, que foram apenas levantados neste artigo, são a escopofilia do primeiro cinema e sua relação com a performance circense, em casos como o peepshow Trapeze disrobing act, em uma análise psicanalista das políticas do olhar. Também não foi possível abordar aqui, porém é cabível de maiores aprofundamentos, a relação específica (e potencializadora) entre as performances de mágica e o cinema, como os filmes de Georges Méliès. Porém, é necessário estudar se, nestes casos, números de mágica já existentes foram adaptados para o cinema, ou se a reprodutibilidade e a montagem do cinema permitiram a criação de novos números que seriam impossíveis fora do dispositivo, além de quais linguagens da performance de palco foram mantidas ou adaptadas para o cinema (gestos, aproximações, interpelações, etc). Trata-se de uma pesquisa extensa, com a necessidade de seleção e análise de um novo corpo fílmico.

\section{NOTAS}

1 “A Biograph produziu vários filmes curtíssimos destinados sobretudo aos peepshows (salas dotadas de quinetoscópios, onde os espectadores espiavam os filmes por visores individuais), nos quais atrizes seminuas davam piscadinhas cúmplices para o espectador, implicando-o abertamente como voyeur dentro da cena." (MACHADO, 1997, p. 81)

\section{REFERÊNCIAS}

ABIRACHED, Robert. “Posfácio - Na escola da pista”. In: WALLON, Emmanuel (Org.). O circo no risco da arte. Belo Horizonte: Autêntica, 2009.
ANNABELLEButterfly Dance.ProduçãodeWilliam Kennedy-laurieDickson.Intérpretes: Annabelle Moore. West Orange: Edison Manufacturing Co., 1894. (1 min.), P\&B.

BAZIN, André. Morte todas as tardes. IN Xavier, Ismail (org.). A Experiência do Cinema. RJ, Graal/Embrafilme, 1983.

BENJAMIN, Walter. A obra de arte na época da sua reprodutibilidade técnica. Porto Alegre: Zouk, 2014. 127 p.

BORTOLETO, Marco Antonio Coelho; MACHADO, Gustavo. de A. “Reflexões sobre o Circo e a Educação Física". In: Revista Corpoconsciência, Santo André, n.12, p. 41 69, 2003.

CAICEDO (with pole). Produção de William Kennedy-laurie Dickson. Intérpretes: Juan A. Caicedo. West Orange: Edison Manufacturing Co., 1894. (19 seg.), P\&B. Disponível em:

<https://www.loc.gov/item/00694115/>. Acesso em: 29 maio 2019.

COSTA, Flávia Cesarino. 0 primeiro cinema. São Paulo, SP: Scritta, 1995. 193p., il. (Classica). ISBN 8573200049 (broch.).

ELSAESSER, Thomas; HAGENER, Malte. $\mathbf{O}$ cinema como olho: A visão e o olhar. In: ELSAESSER, Thomas; HAGENER, Malte. Teoria do Cinema: Uma introdução através dos sentidos. Campinas: Papirus, 2018. Cap. 4. p. 101-129.

GOUDARD, Philippe. “Estética do risco: do corpo sacrificado ao corpo abandonado". In: WALLON, Emmanuel (Org.). O circo no risco da arte. Belo Horizonte: Autêntica, 2009. p. 21-30.

GUNNING, Tom. "The Cinema of Attractions: Early Film, Its Spectator and the AvantGarde". In: ELSAESSER, Thomas; BARKER, Adam. Early cinema: space, frame, narrative. London: Bfi, 1990. p. 55-62.

JÚLIO, Kaliandra Casati; FERNANDES, Guilherme Moreira; TRINTA, Aluizio Ramos. Por trás das lonas: o circo como ritual popular. In:CONFERÊNCIADEFOLKCOMUNICAÇÃO, 
10., 2007. Ponta Grossa: UEPG, 2007. p. 1 - 15. Disponível em: <docplayer.com. br/14484986-Por-tras-das-lonas-o-circo-como-ritual-popular-1.html>. Acesso em: 02 set. 2019.

LEWIS, Robert M (Ed.). From traveling show to Vaudeville: theatrical spectacle in America, 1830-1910. Baltimore: Md: Johns Hopkins University Press, 2007. 384 p.

LUIS Martinetti. Produção de William Kennedy-laurie Dickson. Intérpretes: Luis Martinetti. West Orange: Edison Manufacturing Co., 1894. (16 seg.), P\&B. Disponível em:

<https://www.loc.gov/item/00694130>. Acesso em: 29 maio 2019.

MACHADO, Arlindo. Pré-cinemas \& pós-cinemas. Campinas, SP: Papirus, 1997. 303p.,

il. (Campo imagético). Inclui bibliografia e índice. ISBN 8530804635 : (Broch.).

MANDELL, C. Circo: risco, performatividade e resistência. Sala Preta, v. 16, n. 1, p. 71-81, 1 jul. 2016. Disponível em: <http://www.revistas.usp.br/salapreta/article/ view/111123>. Acesso em: 02 set. 2019.

PENCENAT, Corine. "Atleta, ator, artista?" In: WALLON, Emmanuel (Org.). O circo no risco da arte. Belo Horizonte: Autêntica, 2009.

SANDOW. Produção de William Kennedy-laurie Dickson. Intérpretes: Eugen Sandow. West Orange: Edison Manufacturing Co., 1894.(40 seg.), P \& B . Disponível em:

<https://www.loc.gov/item/00694298/>. Acesso em: 29 maio 2019. STODDART, Helen. “The Circus and Early Cinema: Gravity, Narrative, and Machines". Studies In Popular Culture, [s.l.], v. 38, n. 1, p.1-17, set. 2015. Disponível em: <https://www.jstor.org/stable/44259582>. Acesso em: 27 maio 2019.

THREE acrobats. Intérpretes: The Three Buffons. West Orange: Edison Manufacturing Co., 1899. (34 seg.), P\&B. Disponível em: <https://www.loc.gov/item/96515575/>. Acesso em: 29 maio 2019.

156
TRAPEZE disrobing act. United States: Edison Manufacturing Co., 1901. (2 min.), P\&B. Disponível em: <https://www.loc.gov/item/96514756/>. Acesso em: 29 maio 2019. VERNET, Marc. The Look at the Camera. Cinema Journal, [s.I.], v. 28, n. 2, p.48-63, dez. 1989. Disponível em:

<https://www.jstor.org/stable/1225117?seq=1\#page_scan_tab_contents>.

Acesso em: 30 maio 2019.

WALLON, Emmanuel. “Introdução”. In: WALLON, Emmanuel (Org.). O circo no risco da arte. Belo Horizonte: Autêntica, 2009. p. 15-20.

XAVIER, Ismail. A Janela do Cinema e a Identificação: a opacidade e a transparência. In: XAVIER, Ismail. O Discurso Cinematográfico. 2. ed. São Paulo: Paz e Terra, 1984. Cap. 1.p. 12-15. 